Conference Paper

\title{
Reduction of short circuit current using DC transmission and split- winding power transformer
}

Krakhmalin, I., Chivenkov, A., Vagapov, Y. and Anuchin, A.

This is a paper presented at the 54th IEEE Int. Universities Power Engineering Conference UPEC-2019, Bucharest, Romania, 3-6 Sept. 2019. Copyright of the author(s). Reproduced here with their permission and the permission of the conference organisers.

\section{Recommended citation:}

Krakhmalin, I., Chivenkov, A., Vagapov, Y. and Anuchin, A. (2019) 'Reduction of short circuit current using DC transmission and split-winding power transformer'. In: Proc. 54th IEEE Int. Universities Power Engineering Conference UPEC-2019, Bucharest, Romania, 3-6 Sept. 2019, pp. 1-4. doi: 10.1109/UPEC.2019.8893544 


\section{Reduction of Short Circuit Current using DC Transmission and Split-Winding Power Transformer}

\author{
Igor Krakhmalin \\ Institute of Electrical Power Engineering \\ Nizhny Novgorod State Technical University \\ Nizhny Novgorod, Russia \\ Yuriy Vagapov \\ Faculty of Art, Science and Technology \\ Glyndwr University \\ Wrexham, UK
}

\author{
Alexandr Chivenkov \\ Institute of Electrical Power Engineering \\ Nizhny Novgorod State Technical University \\ Nizhny Novgorod, Russia \\ Alecksey Anuchin \\ Department of Electric Drives \\ Moscow Power Engineering Institute \\ Moscow, Russia
}

\begin{abstract}
This paper discusses a new scheme to reduce the level of fault currents in the feeder cable and power transformer windings under short-circuit conditions. The proposed scheme suggests splitting the feeder cable in two cables and connecting it to a network through two rectifier units. Therefore, the split windings of the power transformer are supplied by a six-conductor feeder using unidirectional dc current. Unidirectional magnetic flux produced by the windings are summarised in the transformer core resulting ac flux to ensure a normal transformer operation. The proposed scheme was analysed under short and open-circuit faults. It has been shown that the short-circuit currents in the cable conductors and transformer windings are reduced in 1.41 times in comparison to a conventional scheme.
\end{abstract}

Keywords-short-circuit; dc transmission; split windings: power transformer; power distribution

\section{INTRODUCTION}

Intensive development of modern electrical power system and integration of distributed generation increases complicity of the power network topology where the distance between the grid nodes becomes shorter. Such an enhancement of power system significantly rises the magnitude of short-circuit current occurred in a faulty part of the network. A short-circuit current which exceeds interrupting capability of protection circuit breakers brings a negative and possibly unrecovered impact on the power system operation and its components [1]-[5]. Conventional solutions to reduce the short-circuit current are based on installation of various current limiters in different parts of electrical power system. According this technique, the limiters should introduce an extra impedance in the circuit currying a fault current and, therefore, provide protection of components in the electrical power system [6],[7]. In the power systems with large penetration of renewable energy the distributed generation significantly contributes in increase of the short-circuit current. In order to limit the fault currents these systems require implementation of comprehensive protection and power flow control devices [8]-[10]. Advanced approach to reduce the short circuit current is related to the network topology reconfiguration. This method has been initially introduced for the optimal power transmission but can be also effectively utilised for short-circuit limitation [11],[12].

This paper introduces a new scheme aimed to improve reliability of operation and to reduce the level of shortcircuit currents in the feeder cable and power transformer windings. The proposed scheme is applicable to MV (medium voltage) power distribution systems $(10 \mathrm{kV})$ and based on modification of the exiting, conventional scheme.

\section{PROPOSED SCHEME}

According the proposed scheme the feeder cable is split onto two cables as shown in Fig 1. Each split cable is connected to the main network through a rectifier unit to ensure current flowing in the cable lines during half-cycle of ac period. Therefore, the transformer is supplied using two three-line cables comprising a six-conductor feeder in which the current is rectified and unidirectional. A power transformer for this application should have three-phase split windings at the high voltage (HV) side. To summarise unidirectional dc currents in the cable conductors the neutral points of the split windings must be jointed [13].
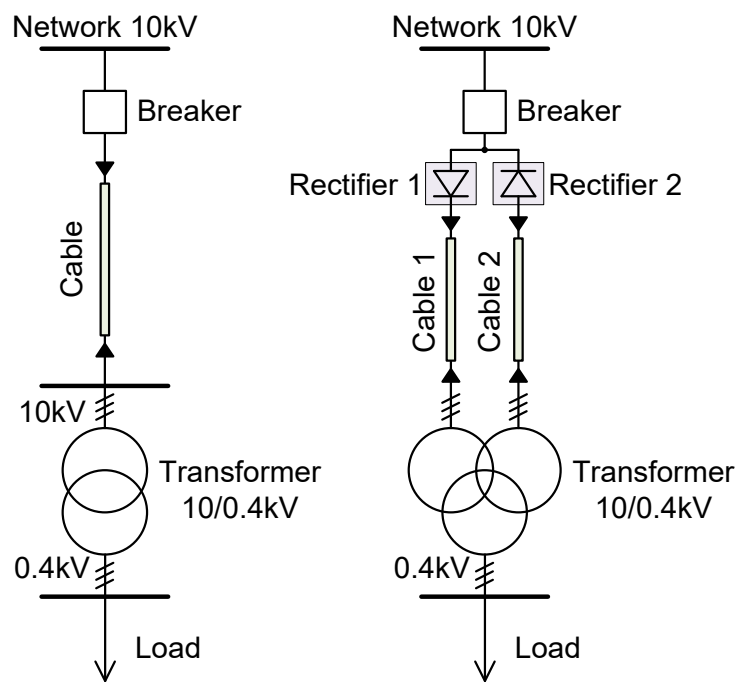

Fig. 1. Conventional and proposed schemes. 


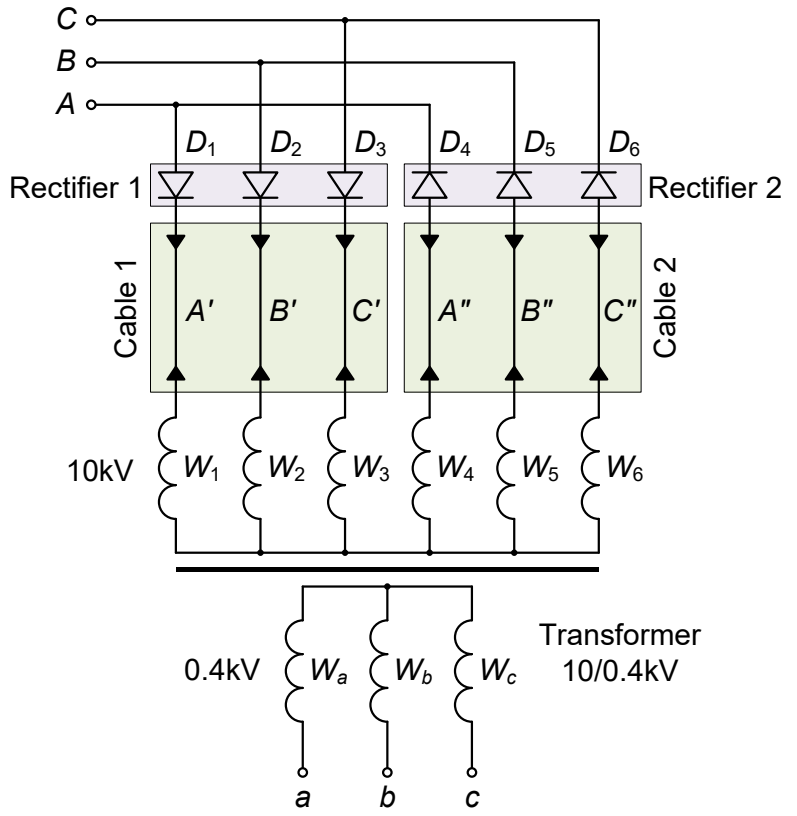

Fig. 2. Circuit diagram of the proposed scheme.

The principle of the proposed scheme operation is shown in Fig. 2. The currents of each phase in the sixconductor feeder are converted into unidirectional current using two rectifier units $\left(D_{1}, D_{2}, D_{3}\right.$ and $\left.D_{4}, D_{5}, D_{6}\right)$, transmitted in a dc from to the power transformer and distributed between two three-phase split windings $\left(W_{1}-W_{4}\right.$, $\left.W_{2}-W_{5}, W_{3}-W_{6}\right)$. The unidirectional currents in the $\mathrm{HV}$ windings $W_{1}-W_{6}$ are summarised to zero in the joint neutral point to ensure balanced operation of the three-phase system. The current flowing through each split winding generates unidirectional magnetic flux in the magnetic core of the transformer. However, all unidirectional magnetic fluxes produced by windings $W_{1}-W_{6}$ are summarised in the transformer core resulting ac flux to ensure a conventional transformer operation. Therefore, the electrical power is delivered through the cables using a dc transmission method whereas the power transformer operates under normal condition with ac magnetic flux waveform in the core.

\section{OPERATION UNDER FAULT CONDITIONS}

The main advantage of the proposed scheme is that under three-phase short-circuit at HV side of the power transformer the fault currents in the cable will be reduced in $\sqrt{2}$ times compared to the conventional scheme. This reduction is achieved due to unidirectional (rectified)
TABLE I. Fault CuRRENTS Under Short Circuits AT HV Side of THE POWER TRANSFORMER

\begin{tabular}{|c|c|c|c|c|c|c|}
\hline Short circuit mode & \multicolumn{2}{|c|}{$\begin{array}{l}\text { Fault current } \\
\text { in cable (pu) }\end{array}$} & \multicolumn{2}{|c|}{$\begin{array}{c}\text { Fault current } \\
\text { in transformer } \\
\mathrm{HV} \text { windings } \\
\text { (pu) }\end{array}$} & \multicolumn{2}{|c|}{$\begin{array}{l}\text { Fault current } \\
\text { in transformer } \\
\mathrm{LV} \text { windings } \\
\text { (pu) }\end{array}$} \\
\hline \multirow{3}{*}{$\begin{array}{l}\text { Three-phase short } \\
\text { circuit }(A-B-C), \\
\text { conventional scheme }\end{array}$} & $A$ & 193.1 & $W_{A}$ & 0 & $W_{a}$ & 0 \\
\hline & $B$ & 193.1 & $W_{B}$ & 0 & $W_{b}$ & 0 \\
\hline & $C$ & 193.1 & $W_{C}$ & 0 & $W_{c}$ & 0 \\
\hline \multirow{6}{*}{$\begin{array}{c}\text { Three-phase short } \\
\text { circuit } \\
\left(A^{\prime}-B^{\prime}-C^{\prime}-A^{\prime \prime}-B^{\prime \prime}-C^{\prime \prime}\right) \\
\text { proposed scheme }\end{array}$} & $A^{\prime}$ & 131.5 & $W_{1}$ & 0 & \multirow{2}{*}{$W_{a}$} & \multirow{2}{*}{0} \\
\hline & $B^{\prime}$ & 131.5 & $W_{2}$ & 0 & & \\
\hline & $C^{\prime}$ & 131.5 & $W_{3}$ & 0 & \multirow{2}{*}{$W_{b}$} & \multirow{2}{*}{0} \\
\hline & $A^{\prime \prime}$ & 131.5 & $W_{4}$ & 0 & & \\
\hline & $B^{\prime \prime}$ & 131.5 & $W_{5}$ & 0 & \multirow{2}{*}{$W_{c}$} & \multirow{2}{*}{0} \\
\hline & $C^{\prime \prime}$ & 131.5 & $W_{6}$ & 0 & & \\
\hline \multirow{6}{*}{$\begin{array}{l}\text { Three-phase short } \\
\text { circuit in the cable } 1 \\
\left(A^{\prime}-B^{\prime}-C^{\prime}\right) \text {, proposed } \\
\text { scheme }\end{array}$} & $A^{\prime}$ & 44.3 & $W_{1}$ & 33.7 & \multirow{2}{*}{$W_{a}$} & \multirow{2}{*}{0.42} \\
\hline & $B^{\prime}$ & 44.3 & $W_{2}$ & 33.7 & & \\
\hline & $C^{\prime}$ & 44.3 & $W_{3}$ & 33.7 & \multirow{2}{*}{$W_{b}$} & \multirow{2}{*}{0.42} \\
\hline & $A^{\prime \prime}$ & 34.0 & $W_{4}$ & 34.0 & & \\
\hline & $B^{\prime \prime}$ & 34.0 & $W_{5}$ & 34.0 & \multirow{2}{*}{$W_{c}$} & \multirow{2}{*}{0.42} \\
\hline & $C^{\prime \prime}$ & 34.0 & $W_{6}$ & 34.0 & & \\
\hline \multirow{3}{*}{$\begin{array}{l}\text { Line-to-line short } \\
\text { circuit }(A-B), \\
\text { conventional scheme }\end{array}$} & $A$ & 173 & $W_{A}$ & 0.5 & $W_{a}$ & 0.5 \\
\hline & $B$ & 175 & $W_{B}$ & 0.5 & $W_{b}$ & 0.5 \\
\hline & $C$ & 1.0 & $W_{C}$ & 1.0 & $W_{c}$ & 1.0 \\
\hline \multirow{6}{*}{$\begin{array}{l}\text { Line-to-line short } \\
\text { circuit in cable } 1 \\
\left(A^{\prime}-B^{\prime}\right), \\
\text { proposed scheme }\end{array}$} & $A^{\prime}$ & 29.0 & $W_{1}$ & 27.8 & \multirow{2}{*}{$W_{a}$} & \multirow{2}{*}{0.6} \\
\hline & $B^{\prime}$ & 29.0 & $W_{2}$ & 27.8 & & \\
\hline & $C^{\prime}$ & 0.5 & $W_{3}$ & 0.5 & \multirow{2}{*}{$W_{b}$} & \multirow{2}{*}{0.7} \\
\hline & $A^{\prime \prime}$ & 27.8 & $W_{4}$ & 27.8 & & \\
\hline & $B^{\prime \prime}$ & 27.8 & $W_{5}$ & 27.8 & \multirow{2}{*}{$W_{c}$} & \multirow{2}{*}{1.0} \\
\hline & $C^{\prime \prime}$ & 1.0 & $W_{6}$ & 1.0 & & \\
\hline \multirow{6}{*}{$\begin{array}{l}\text { Line-to-line short } \\
\text { circuit in cable } 1 \text { and } \\
\text { cable } 2\left(A^{\prime}-B^{\prime \prime}\right), \\
\text { proposed scheme }\end{array}$} & $A^{\prime}$ & 117.0 & $W_{1}$ & 15.5 & \multirow{2}{*}{$W_{a}$} & \multirow{2}{*}{0.56} \\
\hline & $B^{\prime}$ & 15.8 & $W_{2}$ & 15.8 & & \\
\hline & $C^{\prime}$ & 0.7 & $W_{3}$ & 0.7 & \multirow{2}{*}{$W_{b}$} & 06 \\
\hline & $A^{\prime \prime}$ & 15.8 & $W_{4}$ & 15.5 & & .0 \\
\hline & $B^{\prime \prime}$ & 117.0 & $W_{5}$ & 15.8 & $V$ & 10 \\
\hline & $C^{\prime \prime}$ & 0.7 & $W_{6}$ & 0.7 & $w_{c}$ & 100 \\
\hline
\end{tabular}
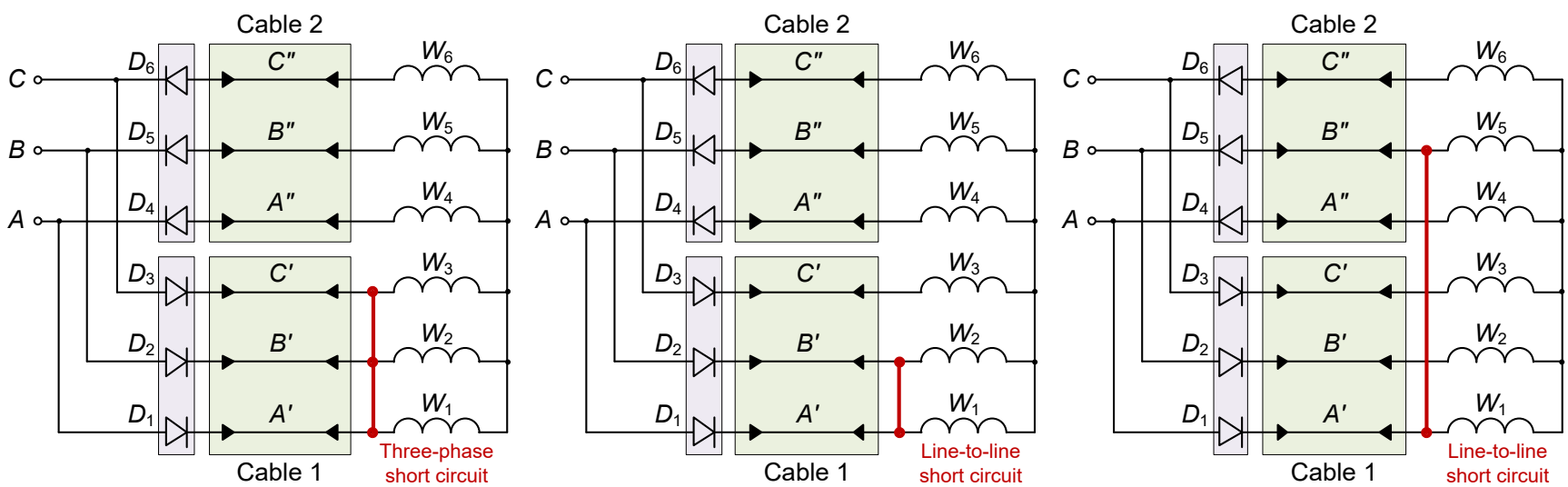

Fig. 2. Short circuits at HV side of the power transformer. 
TABLE II. FAult CurRents Under Short Circuits AT LV Side of THE POWER TRANSFORMER

\begin{tabular}{|c|c|c|c|c|c|c|}
\hline Short circuit mode & \multicolumn{2}{|c|}{$\begin{array}{l}\text { Fault current } \\
\text { in cable (pu) }\end{array}$} & \multicolumn{2}{|c|}{$\begin{array}{l}\text { Fault current } \\
\text { in transformer } \\
\text { HV windings } \\
\text { (pu) }\end{array}$} & \multicolumn{2}{|c|}{$\begin{array}{c}\text { Fault current } \\
\text { in transformer } \\
\mathrm{LV} \text { windings } \\
\text { (pu) }\end{array}$} \\
\hline \multirow{3}{*}{$\begin{array}{l}\text { Three-phase short } \\
\text { circuit }(a-b-c), \\
\text { conventional scheme }\end{array}$} & $A$ & 22.6 & $W_{A}$ & 22.6 & $W_{a}$ & 22.6 \\
\hline & $B$ & 22.6 & $W_{B}$ & 22.6 & $W_{b}$ & 22.6 \\
\hline & $C$ & 22.6 & $W_{C}$ & 22.6 & $W_{c}$ & 22.6 \\
\hline \multirow{6}{*}{$\begin{array}{l}\text { Three-phase short } \\
\text { circuit }(a-b-c) \text {, } \\
\text { proposed scheme }\end{array}$} & $A^{\prime}$ & 16.4 & $W_{1}$ & 16.4 & \multirow{2}{*}{$W_{a}$} & \multirow{2}{*}{23.3} \\
\hline & $B^{\prime}$ & 16.4 & $W_{2}$ & 16.4 & & \\
\hline & $C^{\prime}$ & 16.4 & $W_{3}$ & 16.4 & \multirow{2}{*}{$W_{b}$} & \multirow{2}{*}{23.3} \\
\hline & $A^{\prime \prime}$ & 16.4 & $W_{4}$ & 16.4 & & \\
\hline & $B^{\prime \prime}$ & 16.4 & $W_{5}$ & 16.4 & \multirow{2}{*}{$W_{c}$} & \multirow{2}{*}{23.3} \\
\hline & $C^{\prime \prime}$ & 16.4 & $W_{6}$ & 16.4 & & \\
\hline \multirow{3}{*}{$\begin{array}{l}\text { Line-to-line short } \\
\text { circuit }(a-b), \\
\text { conventional scheme }\end{array}$} & $A$ & 19.7 & $W_{A}$ & 19.7 & $W_{a}$ & 19.7 \\
\hline & $B$ & 19.6 & $W_{B}$ & 19.6 & $W_{b}$ & 19.6 \\
\hline & $C$ & 1.0 & $W_{C}$ & 1,0 & $W_{c}$ & 1.0 \\
\hline \multirow{6}{*}{$\begin{array}{l}\text { Line-to-line short } \\
\text { circuit }(a-b), \\
\text { proposed scheme }\end{array}$} & $A^{\prime}$ & 14.3 & $W_{1}$ & 14.3 & \multirow{2}{*}{$W_{a}$} & \multirow{2}{*}{20.3} \\
\hline & $B^{\prime}$ & 14.2 & $W_{2}$ & 14.2 & & \\
\hline & $C^{\prime}$ & 0.7 & $W_{3}$ & 0.5 & \multirow{2}{*}{$W_{b}$} & \multirow{2}{*}{20.2} \\
\hline & $A^{\prime \prime}$ & 14.3 & $W_{4}$ & 14.3 & & \\
\hline & $B^{\prime \prime}$ & 14.2 & $W_{5}$ & 14.2 & \multirow{2}{*}{$W_{c}$} & \multirow{2}{*}{1.0} \\
\hline & $C^{\prime \prime}$ & 0.7 & $W_{6}$ & 0.7 & & \\
\hline
\end{tabular}

currents through the cable conductors acting over half of period. Another advantage of the proposed scheme is that under short-circuit between conductors in the same cable the fault current is not developed. It is prevented by the diodes in the rectifier unit connected back-to-back in series as shown in Fig. 3. A short-circuit between conductors of different cables is consider as an unusual case.

The data of fault currents in the cable conductors and HV/LV transformer windings under various short-circuit conditions are shown in Table 1. It is assumed that the short circuits occur at the HV terminals of a $1 \mathrm{MVA}, 10 / 0.4 \mathrm{kV}$ power transformer. In order to provide the result comparison, the table also gives the fault currents under the same short-circuits in a conventional scheme with one three-
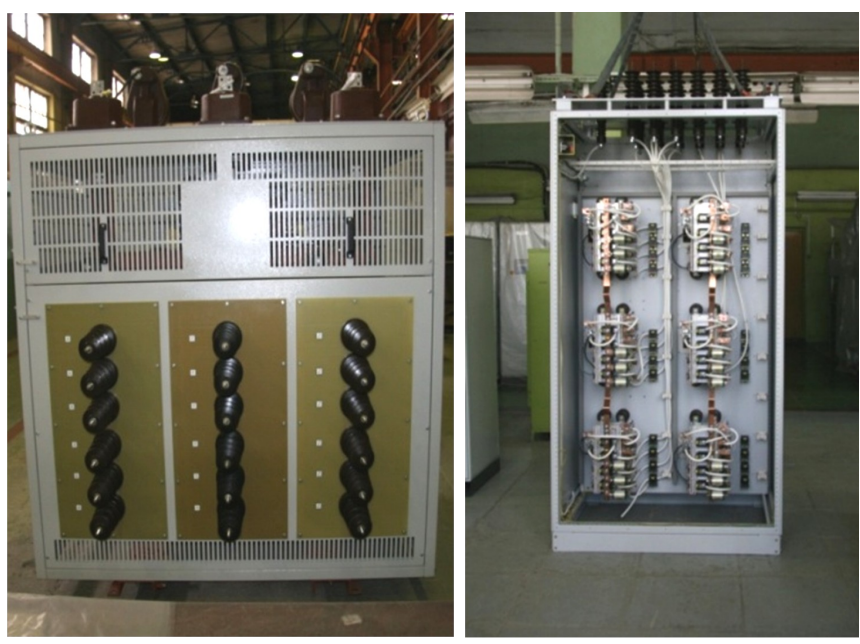

Fig. 4. Split windings transformer and rectifier unit at the distribution substation.
TABLE III. CurRents IN THE CABLES Under Normal Operation AND Open Circuit Fault in the Phase "A"

\begin{tabular}{|c|c|c|c|}
\hline \multicolumn{2}{|c|}{ Mode of operation } & \multicolumn{2}{|c|}{ Current in the cables (pu) } \\
\hline \multirow{4}{*}{ Normal operation } & Conventional scheme & $A, B, C$ & 1.0 \\
\hline & \multirow{3}{*}{ Proposed scheme } & $A^{\prime}, A^{\prime \prime}$ & 0.7 \\
\hline & & $B^{\prime}, B^{\prime \prime}$ & 0.7 \\
\hline & & $C^{\prime}, C^{\prime \prime}$ & 0.7 \\
\hline \multirow{6}{*}{$\begin{array}{c}\text { Open circuit fault } \\
\text { in phase } A\end{array}$} & \multirow{3}{*}{ Conventional scheme } & $A$ & 0 \\
\hline & & $B$ & 0.87 \\
\hline & & $C$ & 0.87 \\
\hline & \multirow{3}{*}{ Proposed scheme } & $A^{\prime}, A^{\prime \prime}$ & 0 \\
\hline & & $B^{\prime}, B^{\prime \prime}$ & 0.62 \\
\hline & & $C^{\prime}, C^{\prime \prime}$ & 0.62 \\
\hline
\end{tabular}

phase cable. It can be seen that the fault current in the cable conductors is reduced $\sqrt{2}$ times under a three-phase symmetrical short-circuit. It means that the cross-sectional area of the cable conductors (and cable cost) for the proposer scheme can be also reduced. However, a much better reduction in the fault currents can be achieved under unbalanced line-to-line short-circuits as shown in Fig. 3.

Table 2 shows the results of analysis of the fault currents in the cable conductors and HV/LV transformer windings under balanced and unbalanced short-circuits at the low voltage side terminals. The results demonstrate that the fault currents in the cables and $\mathrm{HV}$ windings are reduced in comparison to the conventional scheme.

The proposed scheme has been also analysed under open circuit faults. The currents in the cable conductors under open-circuit fault in phase " $A$ " of supplying network are given in Table 3 , whereas the fault currents under opencircuit in the load phase " $a$ " are shown in Table 4 . Table 5 demonstrates the analysis results for varies unbalanced open circuits occurred in the cable conductors of the proposed scheme.

\section{CONCLUSION}

The proposed scheme discussed in this paper provides the reduction of the fault currents occurred under balanced and unbalanced short-circuits. The fault currents are reduced in $\sqrt{2}$ times under a balanced three-phase short-circuit. However, a better reduction in fault currents is achieved at

TABLE IV. CURRENTS IN THE CABLES UNDER NORMAL OPERATION AND Open Circuit Fault in the LoAD Phase "A"

\begin{tabular}{|c|c|c|c|}
\hline \multicolumn{2}{|c|}{ Mode of operation } & \multicolumn{2}{|c|}{ Current in the cables (pu) } \\
\hline \multirow{4}{*}{ Normal operation } & Conventional scheme & $A, B, C$ & 1.0 \\
\hline & \multirow{3}{*}{ Proposed scheme } & $A^{\prime}, A^{\prime \prime}$ & 0.7 \\
\hline & & $B^{\prime}, B^{\prime \prime}$ & 0.7 \\
\hline & & $C^{\prime}, C^{\prime \prime}$ & 0.7 \\
\hline \multirow{6}{*}{$\begin{array}{l}\text { Open circuit fault } \\
\text { in load phase } a\end{array}$} & \multirow{3}{*}{ Conventional scheme } & $A$ & 0.01 \\
\hline & & $B$ & 0.87 \\
\hline & & $C$ & 0.86 \\
\hline & \multirow{3}{*}{ Proposed scheme } & $A^{\prime}, A^{\prime \prime}$ & 0.01 \\
\hline & & $B^{\prime}, B^{\prime \prime}$ & 0.62 \\
\hline & & $C^{\prime}, C^{\prime \prime}$ & 0.61 \\
\hline
\end{tabular}


unbalanced short-circuits. Due to the fault current reduction a cross-sectional area of the cable conductions and the cable cost are also reduced. The short-circuit faults in a single cable do not produce a short-circuit current because of backto-back series connection of the diodes in a rectifier unit. This advantage significantly improves the reliability of the system operation.

\section{TABLE V. CURRENTS Under Open CIRCUIT FAUlts}

\begin{tabular}{|c|c|c|c|c|}
\hline $\begin{array}{c}\text { Mode of } \\
\text { operation }\end{array}$ & \multicolumn{2}{|c|}{ Currents in the cables (pu) } & \multicolumn{2}{|c|}{$\begin{array}{l}\text { Currents in the transformer } \\
\text { LV side windings (pu) }\end{array}$} \\
\hline \multirow{9}{*}{$\begin{array}{l}\text { Normal } \\
\text { operation }\end{array}$} & $A$ & 1.0 & \multirow{3}{*}{$W_{a}$} & \multirow{3}{*}{1.0} \\
\hline & $A^{\prime}$ & 0.7 & & \\
\hline & $A^{\prime \prime}$ & 0.7 & & \\
\hline & $B$ & 1.0 & \multirow{3}{*}{$W_{b}$} & \multirow{3}{*}{1.0} \\
\hline & $B^{\prime}$ & 0.7 & & \\
\hline & $B^{\prime \prime}$ & 0.7 & & \\
\hline & $C$ & 1.0 & & \\
\hline & $C^{\prime}$ & 0.7 & $W_{c}$ & 1.0 \\
\hline & $C^{\prime \prime}$ & 0.7 & & \\
\hline \multirow{6}{*}{$\begin{array}{l}\text { Open circuit } \\
\text { fault in } \\
\text { cable line } C^{\prime}\end{array}$} & $A^{\prime}$ & 1.3 & \multirow{2}{*}{$W_{a}$} & \multirow{2}{*}{0.9} \\
\hline & $A^{\prime \prime}$ & 12.3 & & \\
\hline & $B^{\prime}$ & 14.3 & & \\
\hline & $B^{\prime \prime}$ & 1.0 & $w_{b}$ & 0.8 \\
\hline & $C^{\prime}$ & 0 & & \\
\hline & $C^{\prime \prime}$ & 28.3 & $m_{c}$ & 0.17 \\
\hline \multirow{6}{*}{$\begin{array}{c}\text { Open circuit } \\
\text { fault in } \\
\text { cable lines } \\
B^{\prime \prime}, C^{\prime \prime}\end{array}$} & $A^{\prime}$ & 1.9 & \multirow{2}{*}{$W_{a}$} & \multirow{2}{*}{0.1} \\
\hline & $A^{\prime \prime}$ & 28.4 & & \\
\hline & $B^{\prime}$ & 14.0 & & \\
\hline & $B^{\prime \prime}$ & 0 & $m_{b}$ & 0.00 \\
\hline & $C^{\prime}$ & 14.3 & & \\
\hline & $C^{\prime \prime}$ & 0 & $m_{c}$ & $0.0 \mathrm{~J}$ \\
\hline \multirow{6}{*}{$\begin{array}{l}\text { Open circuit } \\
\text { fault in } \\
\text { cable lines } \\
B^{\prime}, C^{\prime \prime}\end{array}$} & $A^{\prime}$ & 10.2 & \multirow{2}{*}{$W_{a}$} & \multirow{2}{*}{0.7} \\
\hline & $A^{\prime \prime}$ & 4.6 & & \\
\hline & $B^{\prime}$ & 0 & & \\
\hline & $B^{\prime \prime}$ & 28.4 & $r_{b}$ & 0,1 \\
\hline & $C^{\prime}$ & 22.8 & & \\
\hline & $C^{\prime \prime}$ & 0 & $w_{c}$ & 0.11 \\
\hline \multirow{6}{*}{$\begin{array}{l}\text { Open circuit } \\
\text { fault in } \\
\text { cable lines } \\
A^{\prime}, B^{\prime \prime}, C^{\prime}\end{array}$} & $A^{\prime}$ & 0 & \multirow{2}{*}{$W_{a}$} & \multirow{2}{*}{0.6} \\
\hline & $A^{\prime \prime}$ & 13.8 & & \\
\hline & $B^{\prime}$ & 28.4 & \multirow{2}{*}{$W_{b}$} & \multirow{2}{*}{0.1} \\
\hline & $B^{\prime \prime}$ & 0.0 & & \\
\hline & $C^{\prime}$ & 0 & \multirow{2}{*}{$W_{c}$} & \multirow{2}{*}{0.64} \\
\hline & $C^{\prime \prime}$ & 15.3 & & \\
\hline \multirow{6}{*}{$\begin{array}{l}\text { Open circuit } \\
\text { fault in } \\
\text { cable lines } \\
B^{\prime \prime}, C^{\prime}, C^{\prime \prime}\end{array}$} & $A^{\prime}$ & 2.0 & \multirow{2}{*}{$W_{a}$} & \multirow{2}{*}{0.06} \\
\hline & $A^{\prime \prime}$ & 25.1 & & \\
\hline & $B^{\prime}$ & 24.9 & & \\
\hline & $B^{\prime \prime}$ & 0 & $W_{b}$ & 0.00 \\
\hline & $C^{\prime}$ & 0 & & \\
\hline & $C^{\prime \prime}$ & 0 & $W_{c}$ & 0 \\
\hline
\end{tabular}

It should be noted that the proposed scheme is more expensive in comparison to a conventional solution as it requires implementation of a number of additional elements such as rectifier units, two cables and split windings modification of a power transformer. However, in some cases the total cost of the installation can be reduced to the cost of a conventional scheme. The reactors, usually used for short-circuit current limiting, can be excluded from the system due to reduction in fault currents and improvement in reliability. Therefore, the proposed scheme is a promising solution for the power distribution applications where the reliability of electricity supplying and system operation is crucial.

The proposed scheme has been implemented in a distribution power substation supplying an industrial plant. Fig. 4 shows the main components of the installation - the split windings, $10 / 0.4 \mathrm{kV}$ power transformer and a cabinet equipped with the rectifier units. The installation has been in operation for 5 years.

\section{REFERENCES}

[1] A.D. Polykrati, C.G. Karagiannopoulos, and P.D. Bourkas, "Thermal effect on electric power network components under short-circuit currents," Electric Power Systems Research, vol. 72, no. 3, pp. 261267, Dec. 2004.

[2] J.-S. Lacroix, I. Kocar, and M. Belletete, "Accelerated computation of multiphase short circuit summary for unbalanced distribution systems using the concept of selected inversion," IEEE Transactions on Power Systems, vol. 28, no. 2, pp. 1515-1522, May 2013.

[3] M. Tartaglia, and M. Mitolo, "An analytical evaluation of the prospective I2t to assess short-circuit capabilities of cables and busways," IEEE Transactions on Power Delivery, vol. 25, no. 3, pp. 1334-1339, July 2010.

[4] J.-H. Teng, "Unsymmetrical short-circuit fault analysis for weakly meshed distribution systems," IEEE Transactions on Power Systems, vol. 25, no. 1, pp. 96-105, Feb. 2010.

[5] G. Kadkhodaei, K. Sheshyekani, and M. Hamzeh, "Coupled electricmagnetic-thermal-mechanical modelling of busbars under shortcircuit conditions," IET Generation, Transmission \& Distribution, vol. 10, no. 4, pp. 955-963, 2016.

[6] P.T. Ngoc, and J.G. Singh, "Short circuit current level reduction in power system by optimal placement of fault current limiter," International Transactions on Electrical Energy Systems, vol. 27, no. 12, article e2457, Dec. 2017.

[7] M. Saradarzadeh, S. Farhangi, J.L. Schanen, P.-O. Jeannin, and D. Frey, "Combination of power flow controller and short-circuit limiter in distribution electrical network using a cascaded H-bridge distribution-static synchronous series compensator," IET Generation, Transmission \& Distribution, vol. 6, no. 11, pp. 1121-1131, 2012.

[8] M.E. Baran, and I. El-Markaby, "Fault analysis on distribution feeders with distributed generators," IEEE Transactions on Power Systems, vol. 20, no. 4, pp. 1757-1764, Nov. 2005.

[9] T.N. Boutsika, and S.A. Papathanassiou, "Short-circuit calculations in networks with distributed generation," Electric Power Systems Research, vol. 78, no. 7, pp. 1181-1191, July 2008.

[10] M. Firouzi, G.B. Gharehpetian, and B. Mozafari, "Power-flow control and short-circuit current limitation of wind farms using unified interphase power controller," IEEE Transactions on Power Delivery, vol. 32, no. 1, pp. 62-71, Feb. 2017.

[11] Z. Yang, H. Zhong, Q. Xia, and C. Kang, "Optimal transmission switching with short-circuit current limitation constraints," IEEE Transactions on Power Systems, vol. 31, no. 2, pp. 1278-1288, March 2016.

[12] A. Esmaeili, S. Esmaeili, and H. Hojabri, "Short-circuit level control through a multiobjective feeder reconfiguration using fault current limiters in the presence of distributed generations," IET Generation, Transmission \& Distribution, vol. 10, no. 14, pp. 3458-3469, 2016.

[13] A.I. Chivenkov, and I.G. Krakhmalin, "Method of ac three-phase voltage power transmission and system for its implementation," Patent RU2337451, Oct. 27, 2008. 